\title{
Risk factors for the return of mitral regurgitation after coronary artery bypass grafting and mitral valve reconstruction in patients with ischemic cardiomyopathy
}

\author{
Iuliia Kareva ${ }^{1}$, Vidadiue Efendiev ${ }^{2}$, Alexey Nesmachnyy ${ }^{1}$, Sardor Rakhmonov ${ }^{1}$, Alexander \\ Chernyavskiy $^{1}$, Vitaliy Lukinov ${ }^{3}$, Timur Ruzmatov ${ }^{4}$, and Ksenia Gulyaeva ${ }^{1}$ \\ ${ }^{1}$ FGBU Novosibirskij naučno-issledovatel'skij institut patologii krovoobraŝeniâ imeni \\ akademika E N Meshalkina \\ 2, Federal Center cardiovascular surgery "Ministry of Health of the Russian Federation, \\ Krasnoyarsk \\ ${ }^{3}$ Institute of Computational Mathematics and Mathematical Geophysics SB RAS \\ ${ }^{4}$ Intensive Care Unit, Monash Health, Casey Hospital, 62-70 Kangan Dr
}

March 8, 2021

\begin{abstract}
Background and Aim: We aimed to identify risk factors for recurrent mitral regurgitation in two surgical treatment groups: isolated coronary artery bypass grafting $(\mathrm{CABG})$ and CABG combined with mitral valve (MV) repair in patients with moderate ischemic mitral regurgitation (IMR). Methods: A single-centre, prospective, randomised study, which included 76 patients with ICM and moderate mitral regurgitation (MR). Study included two groups: isolated CABG and CABG with MV repair (MVR). Isolated annuloplasty was used to correct mitral insufficiency in the CABG + MVR group. Results: Isolated CABG or CABG combined with MVR in patients with ICM does not lead to a statistically significant decreasing of MR in the long-term period compared to baseline values. However, in one year after surgery, the degree of MR after combined surgery is lower than the initial values. The identification of predictors of the progression of IMR in ICM made it possible to determine the threshold values for the effectiveness of MVR, and the assessment of echocardiographic predictors for annuloplasty helps to choose the right surgical tactic of patients. Conclusions: Coronary revascularization with surgical of IMR in patients with ICM does not increase the number of complications in the early postoperative period compared to the group of isolated CABG. In patients with ICM and moderate MR after isolated CABG, the progression of MR (MR of the 3rd degree, initially $0 \%$, after 12 months $31 \%$, after 36 months $71 \%$; p <0.001) was observed even with an initially moderate expansion of the fibrous ring of the MV.
\end{abstract}

\section{Hosted file}

Risk factors 02.03.2021.pdf available at https://authorea.com/users/400267/articles/512602risk-factors-for-the-return-of-mitral-regurgitation-after-coronary-artery-bypassgrafting-and-mitral-valve-reconstruction-in-patients-with-ischemic-cardiomyopathy 


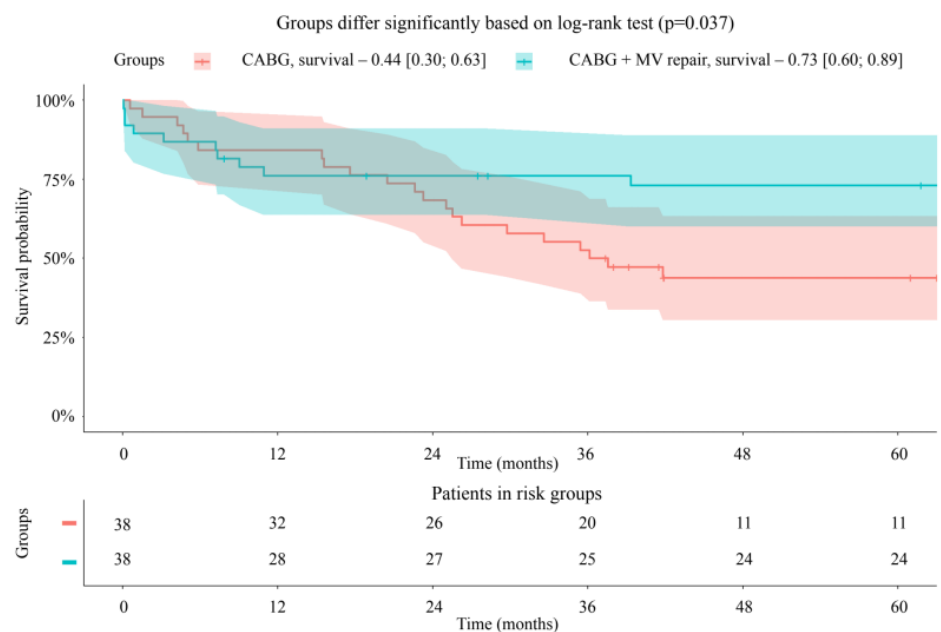




\begin{tabular}{|c|c|c|c|c|c|}
\hline $\begin{array}{c}\text { mitral insufficiency, } \\
\text { degree }\end{array}$ & before surgery, \% & $\begin{array}{c}\text { McNemar test, } \\
p>0,001\end{array}$ & $\begin{array}{l}12 \text { months } \\
\text { after surgery, \% }\end{array}$ & $\begin{array}{c}\text { McNemar test, } \\
p>0,001\end{array}$ & $\begin{array}{l}36 \text { months } \\
\text { after surgery, } \%\end{array}$ \\
\hline 0 & 0 & & 0 & & 0 \\
\hline 1 & 0 & & 9,28 & & 0 \\
\hline 2 & 38 & & 13,41 & & 6,27 \\
\hline 3 & 0 & & 10,31 & & 15,73 \\
\hline total & 38,100 & & 32,100 & & 21,100 \\
\hline $\begin{array}{l}\text { mitral insufficiency, } \\
\text { degree }\end{array}$ & before surgery, $\%$ & $\begin{array}{c}\text { McNemar test, } \\
p>0,001\end{array}$ & $\begin{array}{l}12 \text { months } \\
\text { after surgery, \% }\end{array}$ & $\begin{array}{c}\text { McNemar test, } \\
p>0,001\end{array}$ & $\begin{array}{l}36 \text { months } \\
\text { after surgery, \% }\end{array}$ \\
\hline 0 & 0 & & 22,76 & & 0 \\
\hline 1 & 0 & & 7,24 & & 10,42 \\
\hline 2 & 38 & & 0 & & 9,37 \\
\hline 3 & 0 & & 0 & & 5,21 \\
\hline total & 38,100 & & 29,100 & & 24,100 \\
\hline
\end{tabular}

